\title{
Attributes Indicating Communication Influence on Leadership Development: A Delphi Selection Process
}

\author{
Murendeni Liphadzi, Clinton Aigbavboa and Didibhuku Thwala
}

123 SARChl in Sustainable Construction Management and Leadership in the Built Environment, Faculty of

Engineering and the Built Environment, University of Johannesburg, South Africa, mliphadzi@uj.ac.za

\begin{abstract}
Communication is an essential subject to the built environment and it generally presents special challenges. This is mainly true within the construction industry, were collaboration tends to be characterized by unfamiliar groups of people coming together for short periods before disbanding to their respective construction tasks, moreover the industry is dynamic and complex, which makes communication by industry leaders important. The study aimed at establishing the influence of different communication factors on leadership development in the construction industry. The study adopted the Delphi survey system of data collection to examine the study objective. Delphi experts (Construction specialists and researchers) were engendered from peer-reviewed conference proceedings and the South African construction industry professionals' database. The appraisal of different communication factors was done by identifying the influence of each communication factor on leadership development; these factors were measured between no influence and very high influence. Data collected were analyzed using mean item score and interquartile deviation. Of the different communication attributes evaluated, the ability for leaders to develop active listening skills had a high influence on developing communication attributes for leadership development in the construction industry. The article contributes to the frame of knowledge on leadership development and communication in the construction industry.
\end{abstract}

(c) 2020 The Authors. Published by Budapest University of Technology and Economics \& Diamond Congress Ltd Peer-review under responsibility of the Scientific Committee of the Creative Construction Conference 2020.

Keywords: communication, construction management, leadership

\section{Introduction}

Construction industry leaders serve as main channels to communicate values, strategic changes, and encourage followers within any organization. For example, [12] stated that communication is not only one of the key aspects of leadership performance, but that leadership can be seen productively as a communication process, and some say leadership is communication [3]. In this study, the focus is on the communication attributes that are interlined with leadership. There has been little research on the relationship between leadership and communication, despite studies confirming the importance of the topic, indicating that leaders who pay attention to their communication are more effective agents of change than those who do not [3]. Besides, superior communication styles are linked to their subordinates ' levels of satisfaction [12] and motivation [3]. The research article appraised the Delphi experts' views on the influence of different communication attributes on leadership development within the construction industry. 


\section{Communication and leadership}

According to Kautilya an effective leader has the highest qualities of leadership, intellect, courage, and personal attributes. His research has given a lot of emphasis on communication by leaders. Communication implies effectively reaching and communicating clearly to the targeted audience. He further cited various scenarios where appropriate communication is required to get the things done. It is also important to note that a leader should always demonstrate the right kind of expressions and gestures while communicating. He stated 5 'must have' qualities in a leader, and they are - Visionary, Strategist, Able administrator, effective communicator, and Team Player [5]

Kings and rulers of earlier times can be compared with business leaders of today in most aspects of leadership. There are numerous books, essays, and dissertations on leadership than any other subject of management. The sheer volume of research and writing on the concept of leadership tells us that this is neither a subject that can be easily defined nor will there be a great deal of consensus. There is only one thing for which all these authorities agree, i.e., effective leaders are also effective communicators. However, the opposite is not universally accepted, that good communicators do not necessarily make good leaders [4]. Leaders can achieve success by combining a clear vision of the way forward, honest communication, effective teamwork, and demonstrating that they value the people who work for them.

In these testing times, survival can depend upon being able to keep close to the 'skin' of the business, managing costs tightly, and preparing for the upturn when it comes and for that to happen Leaders need strong communication skills so that they can deal with anything that comes their way [8]. In the construction world, excellent communication is vital for the daily operation of the industry, but can also affect sales and profitability. Without excellent business communication, the internal and external structure of a construction business can face numerous challenges that can ultimately lead to its demise [4].

Bennis describes the skills of a leader as four management competencies. Central to each of these competencies is effective communication. This includes: Management of Attention: this describes how leaders encapsulate a vision, which other people can endorse and buy into as their own. Management of Meaning: Ability to communicate clearly and successfully. Management of Trust: It binds the followers and leaders together. Management of Self: This is what gives leader credibility [9]. Most management training focuses on processes and procedures, which, on its own, is inadequate. Managers and those in positions of leadership need to know how to get the best out of the workforce, which requires a combination of awareness and excellent spoken communication skills.

Whether someone is talking to colleagues or customers, discussing clients, or asking for a promotion, there will be aspects of the interaction that would have had a more significant impact if they were better communicated. Moreover, Managers and other business leaders must also know how to listen, and in order to motivate and influence those around them, those in leadership roles must also have the capacity to "negotiate". However, with effective questioning and open body language it is possible to establish the goodwill of the other party who is then more likely to be motivated by what has been said if they feel that their point of view has been taken into consideration [6]. It is impossible to become a great leader without being a great communicator [2]

It is essential to give emphasis and understand Nonverbal communication, because words only constitute $7 \%$ of the communication and $93 \%$ covers gestures, facial expressions, and body language. The meaning of non-verbal communication is not to be found either in words or the accompanying actions, but rather in the relationship of each other, and also in the context of the situation in which they occur. Nonverbal communication becomes the yardstick against which words and intentions are measured [5]. If you want to become a better communicator, it's vital to become more sensitive not only to the body language and nonverbal cues of others, but also to your own [9]. Considering that communication is essential in human life, a thorough knowledge of the processes and practices of non-verbal communication can help managers to enhance the communication. 
Effective communication skills are an essential aspect of any leader's portfolio of skills and experience [7]. Effective communication skills are tantamount to the success of an organization. Thud making Responsible leaders who communicate effectively. These responsible leaders work hard to prevent bottlenecks and assist keeping the communications channels open throughout the organization by (1) Establishing an appropriate working climate and adjusting their communication behavior to fit the situation. (2) Practicing techniques to improve communication in their organization. These leaders communicate strategically, translating important business objectives into terms through which employees readily understand their value. Communication skills are increasingly regarded as a critical skill set for leaders, particularly in situations where the leader is an instrumental driver of change [10]. It is, therefore, critical for construction leaders to keep enhancing their communication skills.

\section{Methodology}

The Methodology Section details the approach used to assess the effect of different communication factors on the growth of leadership in the South African construction industry. A Delphi survey was conducted amongst 13 experts (academics, built environment professionals and business owners) in the South African construction industry. A Delphi study is a group evaluation instrument compelling qualified experts who have an understanding of the subjects at hand [1]. Each expert was required to meet some of the following criteria; Knowledge: Knows construction management and project management; knowledgeable in leadership re-search; knowledgeable in the field of management theory. Academic Qualification: A degree related to any field and has had occupation and experience focusing on infrastructural development issues, psychology, construction management, project management, and social sciences. Experience: Previously or currently performing consulting and contracting services within the construction industry or any related infrastructure projects. The experts should demonstrate a high degree in the subject matter and also have an extensive theoretical understanding thereof. Research: Has researched leadership and management issues. Membership: Member of a professional organization or represent such an organization. Finally, Enthusiasm: Panel members must be eager to participate entirely in the Delphi study.

The recommendations of [11] were assumed for the current study, whereby they stated that respondents should be enough to consolidate the expert views successfully, but not so large as to analyze the results uncontrollably. With regards to the criteria, five of these criteria items were measured than the customarily advocated two. Experts were required to be in managerial positions and also have an understanding of leadership development. The initial Delphi survey was made up of 20 experts comprising academics and construction professionals who were randomly selected based on the criteria. The experts applied their knowledge on the leadership concepts raised through the developed questionnaire. From the 20 experts requested to participate in the Delphi survey, 13 responded and completed all the three rounds. These amount of experts was considered sufficient grounded on the literature recommendations from scholars who have previously employed the Delphi technique, whereby they cited that, it is viable to have between 6 and 16 experts, this makes 13 experts as seen in the current study reasonable [11]. Likewise, experts were asked to rate the impact factors influencing communication for leadership development in the construction industry as shown in table 1. Data attained from the survey instrument were analyzed from Microsoft Excel. The output from the analysis was a set of descriptive statistics whereby the mean items score and interquartile deviation (IQD) were determined through a scale that reflected no influence, low influence, medium influence, high influence and very high influence.

\section{Findings}

Results from the Delphi survey shows the (11) listed communication measurement variables, that were recognized by the experts as influencing communication for leadership development. When assessed, findings revealed that 10 of the 11 measurement variables achieved consensus with IQD cut off (IQD $\leq 1)$ score (See table 1), and one variable did not achieve the consensus. The 11 variables reached the median score of 7 or more, which implied a high influence (HI: 7-8.99). 
Table 1. Attributes influencing communication

Leaders...

... demonstrate active listening skills

... communicate in a clear manner

... communicate in a precise manner

... demonstrate effective written communication skills

... seek to understand others' verbal and non-verbal communications

... share information appropriately among stakeholders

\section{M}
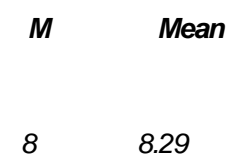

8.29

8.14

8.14

8.21

7.79

8.07
$S D \quad I Q D$

$0.61 \quad 0.00$

$0.77 \quad 0.00$

$0.70 \quad 0.00$

$0.58 \quad 0.00$

$0.83 \quad 0.00$

$0.66 \quad 0.00$

Ability to...

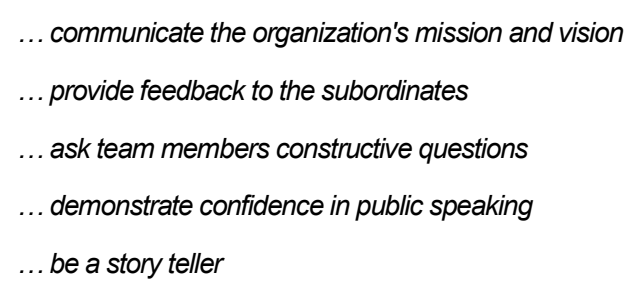

$\begin{array}{llll}8 & 8.14 & 0.74 & 1.00 \\ 8 & 8.36 & 0.70 & 0.00 \\ 8 & 8.21 & 0.87 & 0.88 \\ 8 & 7.75 & 0.68 & 0.00 \\ 8 & 6.57 & 1.87 & 3.00\end{array}$

Findings from the survey divulged that the following 11 communication dimension variables were contemplated by the experts to have varying influence on leadership development in the construction industry.

... demonstrate active listening skills (HI)

... communicate in a clear manner $(\mathrm{HI})$

... communicate in a precise manner $(\mathrm{HI})$

... demonstrate effective written communication skills $(\mathrm{HI})$

... seek to understand others' verbal and non-verbal communications (HI)

... share information appropriately among stakeholders (HI)

... communicate the organization's mission and vision $(\mathrm{HI})$

... provide feedback to the subordinates $(\mathrm{HI})$

... ask team members constructive questions ( $\mathrm{HI})$

... demonstrate confidence in public speaking $(\mathrm{HI})$

... be a story teller (LI)

From the impact assessments of the factors; findings discovered that 10 of the factors had high influence towards leadership development.

\section{Discussion of findings}

Leadership is the most dynamic resource in the construction industry. Moreover, findings about communications indicate that is important to have the different traits as leaders in the construction industry, it further shows that communication training is paramount. Without adequate leadership communication, the industry will not be effective. This section bestows the discussions of the findings from the Delphi survey on the impact of communication variables on leadership development in the construction industry. Results reveal demonstrating active listening skills and the ability to communicate the organizations' mission and vision are fundamental for leadership development and this corresponds with the work by [11]. 
Further findings disclosed that it is essential for construction mangers and personnel to have the ability to provide feedback to those you are leading and this notion supports the effort by [12]

\section{Conclusion and recommendation}

The objective of this article was to evaluate several communication factors that influence leadership development in the construction industry. This was done using the Delphi survey technique. The study shows that communication has a high level of impact on leadership development. This study offers a strong base for communication and leadership development research in the South African construction industry.

\section{References}

[1] Creswell, J. W. (2014). Research design: Qualitative, quantitative and mixed methods approaches. 4th ed. Sage Publications. https://doi.org/10.5539/elt.v12n5p40

[2] Dan B. Curtis, Jerry L. Winsor, and Ron Stephens, (1985). The Ideal Entry- Level and Management Profile, Central Missouri State University Research, 21-25.

[3] Gordon, R. (2010). On entering the workforce", Industrial and Commercial Training, Vol. 40 Iss: 5, 266 - 269. https://doi.org/10.1108/EJTD-09-2014-0067

[4] Hirst, S. (2002). Leadership Communication: A status report, Journal of Communication Management, Henry Stewart Publications, vol.6. https://www.ingentaconnect.com/content/mcb/jcm/2002/00000006/00000004/art00006

[5] Jain, N. \& Mukherjee, S. (2009). Communicating a holistic perspective to the world: Kautilya on leadership, Leadership \& Organization Development Journal, Vol 30 No.5, Emerald Group publishing limited. https://doi.org/10.1108/01437730910968705

[6] Michael, B. Goodman, J. (2007). Tradition and innovation: The China business communication study", Journal of Business Strategy, Vol. 28 Iss: 3, pp.34 - 41. https://doi.org/10.1108/02756660710746256

[7] Naoki, K. (2005). A research paradigm for international business communication", Corporate Communications: An International Journal, Vol. 10 Iss: 2, pp.168 - 182. https://doi.org/10.1108/13563280510596970

[8] Nunnally, J. (1967). Psychometric theory. New York, NY: McGraw-Hill. https://doi.org/10.3102/00028312005003431

[9] Posner, B., \& Kouzes, J. M. (1990). Leadership practices: An alternative to the psychological perspective. In K. E. Clark \& M. B. Clark (Eds.), Measures of leadership (pp. 151-169). West Orange, NJ: Leadership Library of America. https://core.ac.uk/reader/72851134

[10] Roong, S. (2006). Managing international business communication problems at work: a pilot study in foreign companies in Thailand", Cross Cultural Management: An International Journal, Vol. 13 Iss: 4, p.330 - 344.https://doi.org/10.1108/13527600610713422

[11] Rowe, G., Wright, G. \& Bolger, F. (1991). Delphi - A re-evaluation of research and theory. Technological forecasting and social change, 39:238-251. https://www.researchgate.net/publication/228237839_The_Delphi_Technique_A_ReEvaluation_of_Research_and_Theory

[12] Yankov, L., \& Kleiner, B. H. (2001). Human resources issues in the construction industry. Management Research News, 24(3/4), 101-105. 